\title{
Filosofía de la Educación: un aprendizaje
}

\author{
Fernando Bárcena' \\ 'Universidad Complutense de Madrid (UCM), Madrid - Espanha
}

RESUMEN - Filosofía de la Educación: un aprendizaje. Este ensayo tiene como propósito plantear la pregunta por la filosofía de la educación como algo que tiene que ver, no ya con su esencia (una cuestión ontológica), o con su significación (una cuestión hermenéutica), sino, en un sentido deleuziano, con la narración de un aprendizaje: el aprendizaje de un hombre de letras. Planteada de este modo, importa atreverse a formular un interrogante poético: ¿Cómo me hago presente en el presente? De acuerdo con esta tesis, el presente trabajo pretende ofrecer, a modo de relato autobiográfico, el tópico filosofía de la educación, y la pregunta por su ser, como el descubrimiento de un aprendiz y, en este sentido, como una especie de Bildungsroman.

Palabras-clave: Filosofía de la Educación. Filosofía como Forma de Vida. Distancia Poética. Aprendizaje Filosófico.

ABSTRACT - Philosophy of Education: a learning. This paper has as purpose put the question of philosophy of education as something that has nothing to do with his essence (an ontological issue), or with its significance (a question hermeneutics), but with the narration, in a deleuzian's sense, of a apprenticeship: apprenticeship of a man of letters. Raised in this way, what matters, then, is a poetic question: how I being present into present? Accordingly, the present paper aims to offer, by way of autobiographical narrative, the topic philosophy of education such as the discovery of an apprentice and, in this sense, as a sort of Bildungsroman.

Keywords: Philosophy of Education. Philosophy as a Way of Life. Poetic Distance. Philosophical Apprenticeship. 
Filosofía de la Educación

\section{Introducción: el aprendizaje de un hombre de letras}

Voy a rogar al amable lector que tenga paciencia, y solicitarle, al mismo tiempo, cierta benevolencia hacia este escrito, que de todos modos va a tener ocasión de enjuiciar por sí mismo y poner en cuestión, si lo desea. Porque este texto, cuyo asunto es la filosofía de la educación, no pretende describir con plena nitidez un marco epistemológico para esta disciplina ni definir muchas cosas; tampoco se pretende aquí ordenar ningún discurso, sino más bien mostrar las perplejidades, en definitiva los aprendizajes, de alguien que no sabe muy bien qué hace mientras, sin embargo, parece que piensa o elabora cierta clase de filosofía de la educación (cuando enseña esta materia en las aulas de su universidad y piensa junto a sus alumnos, o cuando da conferencias o escribe ensayos y libros).

Lo que voy a tratar de decir en las siguientes páginas está inspirado en dos clases de afirmaciones, que no son simplemente el resultado de horas de estudio y de lectura. Más bien son el fruto de una constatación a la que determinada manera de relacionarme con lo que he venido haciendo a lo largo de una serie de años me ha conducido, en este caso la enseñanza de la filosofía de la educación. En este sentido, estas páginas tienen algo de narrativa personal y autobiográfica. En su ensayo sobre Proust, Deleuze (1996) se refiere al aprendizaje proustiano en los términos del aprendizaje de un hombre de letras, que es un aprendizaje temporal y no meramente el aprendizaje de un saber abstracto. Con frecuencia, el narrador proustiano se queja de cierta indolencia y de cierta pereza, por la que se siente culpable, al no haber conseguido escribir la obra proyectada. Ésta quedará escrita mientras se pregunta, escribiendo, por qué no la culmina. Toda una paradoja.

Salvando todas las distancias, quien esto escribe se siente de la misma manera. Habiendo acumulado muchas páginas en infinidad de cuadernos de notas, no puede (no puedo) sino tener la sensación de que la obra proyectada está, al mismo tiempo, escrita y sin escribir. Parece esparcida en una serie de fragmentos que no son más que una especie de impotencia. Quisiera hablar de esa impotencia.

La primera de las afirmaciones a las que me he referido se la debo a Vincent Descombes, en cuyo ensayo Proust. Philosophie du roman, podemos leer lo siguiente:

$$
\begin{aligned}
& \text { Es una lástima que los filósofos no lean novelas más a me- } \\
& \text { nudo. Al menos eso es lo que parece en vista de la pobreza } \\
& \text { del vocabulario que se utiliza actualmente en la filosofía } \\
& \text { moral. Aunque quizá matizaré mi queja: es una lástima } \\
& \text { que los filósofos no hablen más a manudo de las novelas } \\
& \text { que lees (Descombes, 1987, p. 17). }
\end{aligned}
$$

La pobreza del lenguaje filosófico moderno es una queja muy antigua, y en su último libro Peter Sloterdijk también la retoma a su modo, en su alabanza de la filosofía como una forma de ejercicio. Esta es mi segunda afirmación:

704 Educação \& Realidade, Porto Alegre, v. 38, n. 3, p. 703-730, jul./set. 2013

Disponível em: <http://www.ufrgs.br/edu_realidade> 
¿Es necesario todavía acentuar lo fatal que había de devenir la artificiosidad del conocimiento producida por el idealismo reduccionista de la vieja Academia para la historia de la racionalidad de la cultura Occidental? El logos de Occidente estaba condenado de antemano por las predeterminaciones griegas a un patético empobrecimiento de todas las relaciones con el mundo, y tanto el pensamiento científico como el filosófico siguen hasta hoy en la sombra de esa fatalidad, mientras en la literatura narrativa, en la poesía, en las artes, en el lenguaje corriente en los proverbios, en los mitos y en los conceptos de un espíritu común de las religiones perviven formas de un saber del mundo más rico (aunque menos operativo) (Sloterdijk, 2013, p. 93)

El sentido que ocultan ambas afirmaciones espero contribuir a desvelarlo más adelante, en cierta apelación al estilo (por supuesto, literario y poético) a la hora de pensar lo que la filosofía, en general, y la filosofía de la educación, más específicamente, puede hacer por nosotros como educadores, aunque no entre dentro del registro, dicho con Sloterdijk, de lo operativo. Nada de esto es muy nuevo, desde luego, y ha sido ya discutido muchas veces. Tratar de establecer los lazos entre la filosofía y la literatura, o establecer puentes más sólidos entre lo filosófico y lo narrativo-poético, incluye cierta crítica a la pretensión de hacer valer por filosofía solamente epistemología, mera justificación de los fundamentos verdaderos del conocimiento. Así, Michel Foucault recordaba, en una conferencia dictada en la McGill University de Montreal, en abril de 1971, y que dedicó a Nietzsche, que el mayor descaro de éste consistió en haber tratado de disolver las tesis clásicas según la cuales la verdad es el objeto privilegiado del conocimiento, que un conocimiento sin verdad no es verdadero conocimiento y que la verdad es la verdad del conocimiento. $\mathrm{O}$ sea: en haber puesto en cuestión que la verdad es anterior al conocimiento (Foucault, 2011).

Las tesis de Foucault no niegan la existencia de la verdad en filosofía, sino que la desplaza, con la ayuda de Nietzsche, al ponerla en relación con el sujeto que aspira a ella. No la hacen depender de un método, ni de una intencionalidad, sino, podríamos decir, de avatares azarosos, de encuentros imprevistos entre el sujeto y el mundo y las cosas. Esto, en el marco de este ensayo, es importante tenerlo presente, como veremos.

Hace relativamente poco tiempo pensé que la filosofía de la educación, como la filosofía misma, no era otra cosa que una serie de ejercicios de pensamiento. Eso me pasó leyendo a Pierre Hadot - por ejemplo, la lectura que este hace de Marco Aurelio - y a Michel Foucault, leyendo de nuevo a Hannah Arendt, a Deleuze y volviendo a releer algunos diálogos de Platón o, claro, las mismas Meditaciones de Marco Aurelio. Me pasó leyendo dos veces La regla de juego, del filósofo español José Luis Pardo, y algunos ensayos de Miguel Morey, otro filósofo barcelonés al que admiro y estimo muchísimo. Y después (algo) me pasó.

Educação \& Realidade, Porto Alegre, v. 38, n. 3, p. 703-730, jul./set. 2013.

Disponível em: <http://www.ufrgs.br/edu_realidade> 
Filosofía de la Educación

Me pasó que hablando con Fernando Fuentes Mejías, un brillante doctorando que hace una tesis doctoral conmigo sobre filosofía, educación y el arte de vivir en Foucault, y que en el discurrir de su propia escritura tuvo sus propios encuentros, que renovaron la idea original de lo que quería hacer, mientras viajaba de la filosofía a la música, que es su otra gran pasión; o hablando largamente con Florelle D'Hoest, otra brillante doctoranda mía belga que escribe su tesis también bajo mi dirección, sobre el aprender - yendo de Deleuze a Agamben y del cine de los hermanos Dardenne, a Canino, de Yorgos Lanthimos, y viajando de lo que piensa y lee hasta su propia vida -, me pasó, digo, que me encontré dando mis clases de otro modo, de un modo completamente diferente a como venía haciendo. Esto fue hace muy poco. Observé que mis alumnos de tercer curso del Grado de Pedagogía, en la Facultad de Educación de la Universidad Complutense de Madrid, en este curso 2012-2013, se ponían a pensar junto a mí, pero por ellos mismos, de un modo increíblemente atento y audaz. Pero sabían muy poco de la historia de la filosofía, y como muchos chicos y chicas de su generación, prácticamente nunca habían leído, por ejemplo, un diálogo de Platón entero, algo de Descartes o Rousseau, nada de Kant y mucho menos de los filósofos postmodernos. Me pasó que, no exactamente de repente, pero sí de un modo inusual, entre ellos y yo se produjo un efecto, una especie de roce - entre sus mentes y la mía, entre nuestras mutuas impotencias y nuestras propias voluntades desorientadas - que produjo pensamiento: produjo ejercicios contantes de pensamiento que, en ocasiones, nos dejaban agotados. A veces nos dormíamos, por así decir, y de repente despertábamos, cada uno a su manera, justo en el momento en que más (nos) convenía.

Yo hablaba - sobre esto o lo otro - y ellos, que me observaban, de repente escribían en sus cuadernos de notas o en sus ordenadores portátiles algo, pero lo hacían con el rostro iluminado, con algún gesto que denotaba que les estaba pasando algo. Leyendo en sesiones de tres horas el único libro de Fritz Zorn (2009), semana a semana, y obligándoles yo a que metieran su mente y su cuerpo en el libro, y no permitiendo que se lo llevaran demasiado pronto a lo que de todos modos parecía que ya sabían, porque se lo habían enseñado en otra clase, en otra asignatura, de repente un día comenzaron a desarrollar un tipo de crítica hacia la escritura enferma y dolida de Zorn que me hizo tiritar y temblar. Al principio les obligaba a escribir lo que decidimos llamar microensayos. Se trataba de textos muy cortos, la cara de una página como mucho, que leían cada uno ante el resto del grupo. Y así cada sesión durante varias semanas. Un día, una alumna me dijo: "Fernando, escribí mi primer microensayo, y quedé contenta, pero me dijiste que lo rehiciera; y lo hice. Después escribí otro, que me costó mucho más, y también me dijiste que lo volviera a escribir. Y ahora, en el tercer microensayo, llevo no sé cuántas versiones y me siento impotente".

Yo le dije - pero me costó mucho hacerlo, aunque no tenía más remedio que hacerlo así - que si ese era el caso entonces estaba donde 
tenía que estar, y que tratase de describir, en otro microensayo, lo que le estaba pasando.

Más tarde, ya avanzado el curso, algunos alumnos decidieron hacer sus propias presentaciones de algunos capítulos del libro de Zorn. Y fue increíble. La seriedad con que lo hicieron, el modo cómo se detenían en cada párrafo, los fragmentos del libro de Zorn que usaban en apoyo de sus propios argumentos, las intervenciones del resto de sus compañeros: sus miradas iban del compañero o la compañera que presentaba el capítulo al ejemplar del libro que tenían encima de sus mesas, repleto de papelitos de colores y de notas a lápiz o a bolígrafo. La sala de clase se había convertido en un seminario de lectura de un nivel y madurez que me sorprendió, aunque luego, hablando con mi doctoranda belga sobre ello, entendí algo más, cuando ella me dijo que lo increíble del asunto no estaba que hubiera pasado eso, sino en que no hubiera ocurrido antes, porque las clases, en la Facultad, seguían impartiéndose como si se tratase de un instituto de bachillerato. Había una especie de miedo pedagógico a abrir espacios que permitiesen el ejercicio del pensamiento de nuestros alumnos.

Que me haya ocurrido lo que acabo de relatar - todos tenemos miles de anécdotas que contar al cabo de muchos años de docencia me ha hecho pensar algunas cosas. He vuelto sobre algunos libros que ya había leído y los he entendido de otro modo. Por ejemplo, el siguiente fragmento, que pertenece a los Dialogues entre Claire Parnet y Gilles Deleuze:

\begin{abstract}
La historia de la filosofía siempre ha sido el agente de poder dentro de la filosofía, e incluso dentro del pensamiento. Siempre ha jugado un papel represor: ¿cómo queréis pensar sin haber leído a Platón, Descartes, Kant y Heidegger, y tal o tal libro sobre ellos? Formidable escuela de intimidación que fabrica especialistas del pensamiento, pero que logra también los que permanecen fuera se ajusten tanto o más a esta especialidad de la que se burlan. Históricamente se ha constituido una imagen del pensamiento llamada filosofía que impide que las personas piensen (Deleuze, 2004, p. 17).
\end{abstract}

Aunque éste no es un artículo sobre el pensamiento de Deleuze, he querido incorporar también este fragmento para usarlo como pretexto para mis propios propósitos: pues lo quiero hacer aquí es una especie de elogio de la filosofía (de la educación) como ejercicio de pensamiento.

Un poco después del fragmento arriba citado, Deleuze dice que todo lo que, a partir de esta imagen dominante de la filosofía, tiene que ver con cosas tales como con un pensamiento sin imagen, los nomadismos, las lenguas menores o los tartamudeos de la lengua es aplastado y denunciado como algo nocivo. Está claro que muchas otras disciplinas no estrictamente filosóficas pueden ejercer el mismo papel de represor del pensamiento - desde el momento en que declaran su propio orden 
discursivo -, pero el caso de la filosofía es, por su propia historia, bien característico. La importancia que, históricamente, se ha dado a nociones tales como universalidad, método, juicio, reconocimiento, ideas justas, y otras, parece demostrarlo. Estas nociones sirven como categorías que necesariamente han de ponerse en juego cada vez que, de acuerdo con esta imagen dominante de lo que significa la filosofía, el pensamiento se pone en marcha para pensar la realidad, el mundo, todo lo que, se supone, está ya ahí afuera, plenamente constituido y describible antes incluso de que podamos elaborar cualquier tipo de operación metal sobre lo que hay. Pues de lo que se trata, siempre que la filosofía funciona como tal, es de examinar la realidad, o lo real, a partir de una distancia crítica que, no implicando al pensador en su plena subjetividad en ella, permita examinarla tal y como dicha imagen dominante prescribe. No sé si es por eso, pero Deleuze acaba señalando que hoy “[...] la epistemología ha tomado el relevo de la historia de la filosofía" (Deleuze, 2004, p. 18).

Para mostrar algunas de las implicaciones de un planteamiento como éste, a continuación voy a ofrecer una especie de planteamiento de la filosofía de la educación más o menos clásico, es decir, un tipo de aproximación de esta disciplina tal y como yo mismo, durante mucho tiempo, ofrecía a mis alumnos en la Universidad donde imparto mi docencia.

Este planteamiento que voy a ofrecer tiene algunas características. El lector podrá quizá apreciar que en él existe cierta ambivalencia. A veces yo mismo, casi sin darme cuenta, hago prevalecer cierto criterio epistemológico a la hora de explicar en qué consiste aquello que produzco y hago: filosofía de la educación. En otros momentos, en mi exposición parece que algunas cosas están cambiando, que algo parece querer romperse, aunque sea tímidamente, pero todavía no sabe qué dirección tomar. Y si yo mismo fuera el lector externo que no puedo ser en relación con mi propia exposición diría, quizá, que el autor de las líneas siguientes está aprendiendo algo pero no sabe muy bien qué es. Por decirlo de otro modo: que el autor de esas páginas está aprendiendo mientras estudia, mientras lee y mientras escribe (mientras produce algunas cosas con su pensamiento y las vierte en su escritura), y que ese aprendizaje da la impresión de que en él hay cosas que se modifican, que se transforman y que cambian, pero que nada de eso tiene una forma nítida y acabada. Quizá terminase diciendo que es eso, precisamente, en lo que consiste aprender. Ir tomando una forma pero no ver la forma completamente acabada.

Yo podría muy bien exponer mi concepción actual de la disciplina que enseño y en la cual investigo ignorando todo lo que he pensado, escrito y leído antes, y que en muchos casos nada tiene que ver con lo que ahora pienso, como si nada de lo anterior hubiera en realidad ocurrido. Podría hacerlo, pero entonces no diría la verdad. Habría descorrido el velo destapando otra cosa que lo que debía desvelarse y mostrarse a la

708 Educação \& Realidade, Porto Alegre, v. 38, n. 3, p. 703-730, jul./set. 2013. Disponível em: <http://www.ufrgs.br/edu_realidade> 
luz. Habría, entonces, negado mi historia, es decir, habría saltado por encima de mi propio relato, de mi propia novela de formación. Mi aprendizaje es, como anuncié antes, algo parecido, pero salvando todas las distancias, a lo que Deleuze dice a propósito de Marcel Proust: el aprendizaje de un hombre de letras. Esto es: el aprendizaje de alguien que ha intentado hacer cosas con palabras, con el lenguaje, con la escritura y con los libros que leía y estudiaba. Al mismo tiempo, estas actividades, resumidas en el estudiar, el leer y el escribir, me han permitido pensar, pero solo hasta cierto punto. Me dieron la sensación de que hacía cosas, algunas cosas, pero también que no hacía nada, que no producía nada, pues, de todos modos, ¿qué significa producir palabras si no soy un poeta, ya que son ellos los que las producen pero no las usan? Yo solo puedo usarlas - es decir, aprenderlas - pero no darlas a luz.

\section{Cuando el Aprendiz se Encontró con el Acontecimiento} sonal.

Empecemos, pues, con el relato; con este relato de formación per-

No se dice nada nuevo, me dije un día, si se afirma que la educación puede ser considerada, en primer lugar, como un objeto de conocimiento y, en segundo término, como una acción destinada a articularse a través de la experiencia. La educación - pensé durante mucho tiempo - enuncia un saber y, al mismo tiempo, la experiencia de una actividad orientada a la transformación del individuo y la sociedad a través de las generaciones. Esta última afirmación es bastante reciente en mí: la idea de un encuentro entre generaciones como un terminante fundamental en un pensamiento sobre la educación. La educación, entonces, es la experiencia de un encuentro (o relación) y una transmisión de la cultura (la durabilidad del mundo) entre generaciones en la filiación (y la discontinuidad) del tiempo ${ }^{1}$. Como saber referido al estudio de la educación, en este sentido entendida, la filosofía de la educación posee una dimensión teórica - aspira a la elaboración, crítica y análisis de conceptos - y una dimensión práctico-experiencial; pues la educación - siendo a la vez proceso y resultado - es lo que a uno le pasa cuando se está (trans) formando. Es, podríamos decir, un acontecimiento.

La categoría de acontecimiento es, filosóficamente, bastante escurridiza. Se ha convertido en muchos foros una especie de significado despótico que, pretendiendo decirlo todo, nada dice muchas veces. Es como una carta de presentación para cierta manera de hacer filosofía de la educación desde un lenguaje alternativo al supuestamente dominante. Durante años intenté dar cierto contenido, a partir de lo que a mi mismo me había pasado, a esta noción. Y así consideré que siempre que hay o se da un acontecimiento - sea constructor o destructor - hay una potencia de experiencia para el hombre. Podemos decir, entonces, que un acontecimiento es una experiencia de concernimiento personal. Cuando se da un acontecimiento decimos que lo imprevisible y sorprendente ha tenido lugar, y con ello podemos querer decir, al menos,

Educação \& Realidade, Porto Alegre, v. 38, n. 3, p. 703-730, jul./set. 2013. 709

Disponível em: <http://www.ufrgs.br/edu_realidade> 
tres cosas: que algo nos da a pensar; que alguien realiza una experiencia; y que alguien, como consecuencia de eso que le pasa, ya no es el mismo que antes, que es discontinuo con respecto a un tiempo vital y biográfico anterior. El acontecimiento, por tanto, nos da a pensar, nos permite realizar una experiencia nueva, e introduce la discontinuidad en el tiempo vital o biográfico. El centro del acontecimiento es, entonces, la experiencia del aprender: el paso del antes al después, de la potencia al acto, de lo implícito a lo explícito (Pardo, 2004). Y la filosofía de la educación trata de explorar la educación desde este punto de vista.

Ahora bien, todo filosofar construye conceptos y también elabora, o puede elaborar, teorías; es, en el sentido griego del término, theorein, algo conectado con la visión, con el mirar y, por tanto, con cierta capacidad para prestar atención. En el transcurso de una conversación con Arnold Davidson, Pierre Hadot, recordando a Merleau-Ponty, decía que "[...] la verdadera filosofía es volver a aprender a ver el mundo" (Hadot, 2001, p. 208): extrañamiento, maravillarse, admirarse ante lo que surge de forma inexplicable. La filosofía manifesta una aporia originaria y radical que Sócrates encarna a la perfección y también materializa:

\begin{abstract}
¿Cómo llegar a ser lo que no se es? ¿Cómo aprender lo que no se sabe? El problema del comienzo se les planteó a los griegos en primer lugar bajo la forma de ese asombro ante la más concreta experiencia humana: la del crecimiento, y más precisamente, el crecimiento espiritual, la máthesis (Aubenque, 1974, p. 426).
\end{abstract}

En el caso de la filosofía de la educación, esta mirada (y esa admiración o asombro) se vierte hacia esa parcela de lo real que llamamos educación. En la esfera de la educación, entendida como una experiencia humana histórica y existencialmente fundamental, aprendemos a descubrir los acontecimientos que, al darnos a pensar, originan los conceptos con que los que nombramos y pensamos. Así, Deleuze y Guattari señalan que "[...] la filosofía es el arte de formar, de inventar, de fabricar conceptos" (Deleuze y Guattari, 2005, p. 8); pero el concepto - añaden de inmediato - "[...] expresa el acontecimiento, no la esencia o la cosa" (Deleuze; Guattari, 2005, p. 26). La filosofía nos enseña a ver lo que, teniéndolo delante, sin embargo no vemos del todo, porque aún no hemos caído en la cuenta de su importancia. Nos ayuda a estar presentes, y vivos, en lo real. Pero, entonces, el ejercicio filosófico, más que una relación con lo eterno o con lo que permanece siempre estable, está vinculado con el devenir, con lo que siempre es o puede ser de otra manera de cómo es; con el acontecimiento: "Filosofía del presente, filosofía del acontecimiento, filosofía de lo que ocurre”, decía Foucault (2010, p. 817).

En educación, lo que se puede poner en práctica, dentro de un curso de acción, también se puede transformar en palabras, elaborar conceptos y discutirse inteligentemente. En la medida en que todo ello se haga con cierto rigor, seriedad y profundidad, esta discusión incluirá tanto descripciones generales de lo que se hace como recomendaciones 
acerca de lo que se puede o no se puede hacer en distintas situaciones más específicas. De este modo, el discurso pedagógico estará formado por teorías, o teorizaciones, educativas expresadas de forma más o menos formal. La investigación en filosofía de la educación se ocupa de todo ello, examinando el aparato conceptual que teóricos y practicantes de la educación adoptan cuando la piensan o cuando la hacen. Este examen implica la capacidad para hacerse preguntas, para realizar problematizaciones, y ejercer la crítica como una actitud ética que mira o atiende a la realidad, al presente. Se trata de querer saber, no para confirmar lo que ya sabemos, sino para pensar de otro modo.

Por eso decimos que la filosofía de la educación es una disciplina que elabora un tipo de reflexión cuyo tema es el análisis y exploración de los supuestos críticos de la educación, entendida en el anterior sentido. Un supuesto tiene tres acepciones principales: a) es aquello que, no siendo verdadero, pretende hacerse pasar por cierto; b) se refiere a lo que es posible que sea cierto o verdadero, pero no se ha demostrado todavía; y c) supone la idea, juicio o teoría que se supone verdadera, aunque no se haya demostrado o confirmado, y a partir de la cual se extrae una consecuencia o una conclusión, o se derivan hipótesis. Las dos primeras acepciones refieren un momento ético en relación con la verdad (la exigencia de no hacer pasar por verdadero lo que es mera falsedad, y el imperativo de no adelantar nuestros juicios valorativos antes de hacer las demostraciones pertinentes); en ambos casos, la cuestión de la verdad tiene relación con determinadas cualidades éticas (la paciencia y la honestidad en la búsqueda de pruebas, la franqueza en el discurso; la parresía griega o palabra franca, es decir, el coraje de la verdad, entre otras) (Foucault, 2009). La última acepción introduce un momento epistemológico en relación con lo que ha de entenderse como saber o conocimiento científico; las condiciones que constituyen un saber como científico.

Los supuestos críticos de educación se refieren - en su doble componente ético y epistemológico - al conjunto de principios, condiciones y presupuestos que, históricamente, se han ido añadiendo a la educación. Los denominamos críticos porque su análisis requiere el ejercicio de cierta capacidad de juicio y de discernimiento (un concepto implica operaciones de análisis, separación y reunión de elementos dispares), y porque, al mismo tiempo, constituyen elementos que siempre ponen en riesgo, o en crisis, la educación si no se exploran, analizan o se piensan con detenimiento. Un supuesto crítico en educación, supone, entonces, una actividad de pensamiento capaz de problematizar, movilizar, deconstruir. Lejos de poder sostener que el pensamiento tiende voluntariamente al descubrimiento de la verdad -o de las verdades, cualesquiera que sean, y sea en el ámbito en el que sean -, la verdad es algo que viene, muy a menudo, por azar, es decir, de modo involuntario: es un encuentro fortuito, una revelación, un acontecimiento. Por eso conviene aprender a pensar de nuevo, en el sentido de inquietar la actividad del

Educação \& Realidade, Porto Alegre, v. 38, n. 3, p. 703-730, jul./set. 2013.

Disponível em: <http://www.ufrgs.br/edu_realidade> 
pensamiento - hacer que sea una experiencia viva -, y de dar a las cosas un nuevo giro, una nueva dirección o inclinación. Eso es lo que significa reconstruirlo: no dar las cosas por permanentes ni eternas.

\section{De Cuando el Aprendiz Buscó un Estilo}

Hasta aquí, un aprendiz de filósofo (en educación) expone, más o menos articuladamente, un conjunto de ideas que eran, en su origen, una serie de apuntes en un cuaderno de notas acumuladas a lo largo de los años. Pero hay que avanzar. Pues encontrarse con el acontecimiento no significa solo haberlo descubierto como concepto, y perseguirlo en lecturas que se suceden. Significa habitarlo de otro modo y darse cuanta, progresivamente, que hay cosas que parece que cambian. Por ejemplo, cierto estilo de pensar y cierto estilo de poner los pensamientos por escrito.

Así, la posición de Deleuze, en el fragmento citado más arriba, recuerda un poco lo que Heidegger ya dijo en su curso Wass heiss denken?, impartido en la Universidad de Friburgo de Brisgovia:

El que se dé un interés por la filosofía, todavía no es un testimonio fehaciente de la disposición a pensar [...] Por el contrario: la ocupación con la filosofía puede simularnos muy pertinazmente la apariencia de que pensamos puesto que filosofamos sin cesar (Heidegger, 2005, p. 17).

Heidegger comienza sus lecciones diciendo que nos adentramos en lo que es pensar cuando pensamos nosotros mismos. Para tener éxito en este intento hemos de estar dispuestos a un aprendizaje del pensar.

Pues bien, a pensar del juicio de Deleuze, a saber, que "[...] en la actualidad incluso se puede decir que la historia de la filosofía ha fracasado" (Deleuze, 2004, p. 18), lo que yo pienso es que una disciplina como la filosofía (de la educación) es una especie de Bildungsroman, una especie de relato de formación (y que se ocupa de lo que la formación es) de modo tal que preguntas del tipo ¿Qué es la filosofía de la educación? revisten una dimensión ontológica que no se ajusta a la experiencia, específica de ella, del devenir. Imagino que la primera pregunta que un profesor de filosofía de la educación hace cuando inicia un curso sobre materia es esta: ¿qué es la filosofía de la educación? Es la pregunta que parece dotar de crédito epistemológico a lo que hacemos, cuando nos mostramos ante nuestros alumnos como profesores, y como investigadores, de este campo de saber; yo mismo empecé de este modo durante mucho tiempo. El asunto no mejoraría añadiendo a esta pregunta el interrogante, quizá más hermenéutico, del ¿qqué significa una filosofía de la educación?, interrogante que la vincula a la cuestión de la mera producción de interpretaciones.

Si la primera pregunta está presidida por cierta invocación esencialista, la segunda conecta esta disciplina con la pretensión, de aspiración universalista, de interpretación, que anhela la producción de

712 Educação \& Realidade, Porto Alegre, v. 38, n. 3, p. 703-730, jul./set. 2013. Disponível em: <http://www.ufrgs.br/edu_realidade> 
significados. Pero lo que se gana en significado se pierde en sentido, y acabamos olvidando una relación con el mundo fundada en la producción de la presencia. El término presencia-de prae-essere-se refiere aquí a una relación espacio-temporal con el mundo: lo que se hace presente es una especie de producción poética que busca hacerse tangible en su impacto inmediato en el cuerpo, lugar privilegiado del espacio y el tiempo humanos (Gumbrecht, 2010).

Todo hacer humano - desde fabricar una silla hasta hacer filosofía de la educación- se puede entender, e históricamente ha sido así, como una práctica. Se trata de la manifestación de una voluntad que busca producir un efecto concreto. Habitamos la tierra productivamente, o sea, prácticamente, produciendo con nuestro hacer efectos. Estos efectos pueden ser externos a nuestra actividad, o pueden ser concebidos de otro modo: pudiera ser que ese efecto no sea otra cosa que nuestra propia presencia en nuestro hacer, en nuestra actividad. Agamben llama a esto producción hacia la presencia: hacer pasar algo del no-ser al ser, o de la ocultación a la plena luz. La antigua palabra poíesis es lo que significaba, según la interpretación de Agamben: "El carácter esencial de la poíesis no estaba en su aspecto de proceso práctico, voluntario, sino en su ser una forma de verdad, entendida como desvelamiento, $\dot{\alpha}-\lambda \dot{\eta} \theta \varepsilon 1 \alpha$ " (Agamben, 1988, p. 113).

De acuerdo con estas consideraciones preliminares, voy descubriendo que la pregunta por la filosofía de la educación es, o podría ser, algo que tiene que ver, no ya con la esencia o con la significación, sino con la relación, en el sentido aludido, entre la experiencia y el sentido. Esta relación supone un interrogante poético (por tato, ni ontológico ni hermenéutico), siguiente: ¿Cómo me hago presente en lo que hago y en lo que pienso?

Las implicaciones de un interrogante de estas características son diversas; y a mi me gustaría destacar sobre todo una. Del mismo modo que en la literatura es posible contar historias formadas por meras insignificancias, casualidades y efectos imprevistos, sin incurrir en una vulgaridad ausente de una idea narrativa directriz, así también en el terreno de una filosofía (de la educación) sería factible producir pensamientos no desde una razón desvinculada de los acontecimientos - que son los que nos dan a pensar-, sino desde experiencias concretas que reflejan las transformaciones en las que nos hallamos inmersos. El propósito de un filosofar educativo no sería ya la pretensión de cambiar lo que hay, sino aprender a mirar lo que ya vemos, pero no nos damos cuen$t a$ : prestar atención a lo que hay haciéndonos presentes en la realidad. Atender significa aquí cuidar (cuidado, preocupación). Tener cuidado con algo es poner interés en ello; interés es ser entre las cosas, hallarse en medio de ellas, permanecer próximo o cercano a ellas; en una especie de acto de presencia. La palabra francesa présent es bastante indicativa de esto: en francés, el adverbio de lugar près significa proximidad, cercanía, de modo que todo presente (présent) evoca la dimensión de la cer- 
canía, de la proximidad. No hay aprendizaje, entonces, que no suponga un hacerse presente en las cosas. Hacernos presente en algo implica pararse, detenerse, aminorar la marcha y aproximarse a algo.

Estas suposiciones requieren, para la filosofía de la educación, poder reivindicar un estilo de escritura que toman los acontecimientos pensados por ella no como un caso más, sino como un pliegue de lo real, como una ocasión única para pensar singularmente aquello que, en el terreno de lo dado, se escapa a los marcos de explicación ya establecidos. Ese estilo es el del ensayo, y la vocación ensayística de la filosofía de la educación afecta también al pensar. Se trata de esos ejercicios de pensamiento que buscan una ganancia en cómo pensar en la brecha abierta entre el pasado y el futuro. No nacen de una debilidad resignada, sino de un empeño por habilitar un espacio intermedio entre la finitud humana y su interminable ansia de saber. El ensayo se erige en una forma que busca hacer justicia a la complejidad de lo real, articulando especulación y experiencia cotidiana. Nos dice que es a partir de los lugares cotidianos donde comienza la exigente tarea que tiene asignada una filosofía de la educación. El ensayo (como género en filosofía de la educación, es decir: el ensayo de filosofía de la educación), hace una especie de amable desafío al ideal de la clara et distincta perceptio y de la certeza libre de dudas ${ }^{2}$.

\section{La Distancia Poética en Educación: una discusión}

Para entender bien las anteriores notas, al aprendiz de filósofo (de la educación) no le queda más remedio que tratar de recordar la existencia de dos grandes tradiciones filosóficas que dan lugar a sendas orientaciones de la filosofía de la educación: la tradición crítico-hermenéutica (la filosofía como discurso racional) y la tradición ascético-estético-existencial (la filosofía como forma de vida). Estas dos tradiciones están sostenidas en dos modos de entender la filosofía, que se han hecho clásicos ya: el primero, representado por los dos primeros capítulos de la Metafísica de Aristóteles, y el segundo, por la Apología de Sócrates, escrita por Platón. La filosofía, pues, como expresión del ocio perfecto que conduce al hombre al saber por el saber, sin necesidad de emoción alguna - en el primer caso -, y - en el segundo - la filosofía como un modo de vivir ${ }^{3}$.

a) La primera tradición, cuya contribución al desarrollo del pensamiento filosófico es indiscutible, hace de la realidad un mero objeto de conocimiento. El trabajo filosófico consiste, básicamente, en examinarla a partir del establecimiento de una distancia crítica con dicha realidad, para garantizar la imparcialidad y la objetividad del conocimiento; para asegurar cierto ideal de desvinculación del yo con el mundo (Taylor, 2006; 2013 y ss.). Aquí, es la realidad la que es examinada por el pensador; la filosofía de la educación, se ha dicho, es una “[...] disciplina académica especializada en el análisis y la comprensión de amplios procesos de construcción de teorías y el examen de sus premisas 
de base, con el fin de examinar y revelar los valores que inciden a las prácticas humanas académicas" (Holma, 2009, p. 325).

También se ha señalado que su tema son "[...] las cuestiones éticas y filosóficas perennes sobre la responsabilidad, así como problemas epistemológicos sobre el conocimiento y su justificación" (Holma, 2009, p. 325) O bien que "[...] es una tarea central de la filosofía de la educación examinar los marcos conceptuales que los académicos y los prácticos emplean para interpretar la experiencia, expresar sus propósitos, enmarcar problemas y conducir sus investigaciones" (Vokey, 2009, p. 339).

Estas citas sugieren que argumentar, evaluar, explorar, contrastar teorías son actividades centrales del trabajo intelectual en esta visión dominante de la filosofía de la educación, entendida como una especie de reflexión de segundo orden que contempla a la investigación educativa, y a su práctica, como un objeto de conocimiento. Se trata de una visión de la filosofía de la educación inserta en la tradición crítica establecida por Kant que se focalizada sobre las condiciones internas y las condiciones externas de validación de la producción del conocimiento; pero se trata, también, de una tradición que incorpora elementos de la tradición filosófica práctico-hermenéutica que busca comprender las prácticas y cualificarlas a través de contextualizaciones históricas, iluminando horizontes de significado. Michel Foucault se refirió, de algún modo, a esta tradición denominándola momento cartesiano - sin pretender querer decir con dicha expresión que fuera Descartes su inventor -, un momento en el que "[...] la edad moderna de la historia de la verdad comienza a partir del momento en que lo que permite tener acceso a lo verdadero es el conocimiento, y sólo el conocimiento" (Foucault, 2002, p. 36); o lo que es igual, que el filósofo (el pensador) puede acceder a la verdad, a lo verdadero, sin necesitar transformarse, modificarse en ningún sentido sustancial del término.

De acuerdo con esta tradición, de lo que se trataría es de comprender e interpretar, pero también de juzgar y criticar la coherencia, los valores, las pretensiones del conocimiento, la racionalidad y los fines, los principios, los argumentos que se hacen presentes en los discursos y en las prácticas relacionadas con la educación. Esta tradición concibe el trabajo en filosofía de la educación como algo relacionado con el juicio, la clasificación, la categorización, la justificación, la selección, la clarificación de conceptos, la interpretación, la explicación y, en este sentido, es crítica del mismo modo que está orientada a pretensiones de validez, tanto ético-normativas como epistemológicas.

Resumiendo: para esta tradición el investigador, o el pensador, queda concebido como un sujeto del conocimiento que sitúa a la realidad (sea la investigación educativa, la práctica educativa o las políticas educativas) bajo el examen de su propio pensamiento (teoría, conceptos, conocimiento). Es la realidad, situada frente al sujeto que la piensa, la que es sometida a examen desde una distancia crítica. Cuanto más queremos conocer la realidad de que se trate, más saber tenemos que 
poner entre nosotros y el objeto de nuestro pensamiento, y en consecuencia mayor es la distancia que nos separa de él. El sujeto del conocimiento debe mantenerse lo más alejado posible de ella para observarla con cierta objetividad, imparcialidad y neutralidad. No hacerse presente en ella es la condición de posibilidad para acceder a la verdad de la realidad.

b) La segunda tradición hace de la realidad un lugar de presencia. Sugiere que es haciéndonos presentes en lo real, mediante el establecimiento de una suerte de distancia apropiada, como el pensador - entendido ahora como un sujeto de la experiencia - se examina a sí mismo y puede entonces trans-formarse ${ }^{4}$. La llamo presencia poética porque lo poético hace referencia, como dije antes leyendo a Agamben, a lo que originalmente significaba el trabajo del artista-poeta: hacer salir una cosa de la nada al ser, o sea, hacerla visible o presente: llevarla hacia su visibilidad. La palabra educación, entendida - de acuerdo a una de sus posibilidades etimológicas - como e-ducere, viene a significar un salir afuera -una salida, un viaje, una experiencia, una exposición - y un $s a$ car hacia fuera - tornar visible - al sujeto resultado de una formación, de una transformación y de un cuidado de sí (epimeleia heautou), como decían los griegos.

Esta tradición agrupa a esos pensadores para los cuales el saber y el conocimiento del mundo suponen una relación de presencia (poética) con lo que se aspira a conocer. La antigua formulación de la filosofía como forma de vida se inscribe en esta segunda tradición, y tiene mucho que enseñarnos a quienes nos dedicamos a la educación, tengamos o no vocación intelectual por la filosofía de la educación. Porque lo real no es meramente una cosa, sino un acontecimiento; no un problema, sino una cuestión abierta; no reclama tanto soluciones como respuestas; no es representación sino un lugar de presencia. Lo real no es lo que debería ser, sino lo que, de hecho, ya es (Larrosa, 2010, p. 109).

Quizá sorprenda la alusión a lo poético en esta segunda formulación. No se trata de invocar ningún esteticismo, ni procurar un embellecimiento del discurso filosófico en educación. A menudo ocurre que, muy al contrario, buena parte de los discursos pedagógicos que pasan por sostenerse en cierto trabajo filosófico previo son, en el fondo, discursos vacíos, aunque estén bien llenos de otra clase de abstracciones. Quiero insistir en este punto, que me parece importante, no sólo porque tanto en relación al conocimiento como en el plano de la relación pedagógica es el arte de las distancias (ni muy cerca ni muy lejos), lo que nos ayuda a definir nuestra posición y nuestra perspectiva con respecto a lo otro, sino por un motivo quizá más radical.

En sus Observaciones, Wittgenstein decía, refiriéndose a su propia obra, que "[...] creo haber resumido mi postura respecto a la filosofía al decir que la filosofía debería ser una obra poética" (Wittgenstein, 1989, p. 52). Para Wittgenstein, ética y estética son lo mismo, lo que, en el marco del Tractatus, significa que existe un vínculo o nexo entre la búsque- 
da de una justa visión del mundo (ejercitado en la contemplación) y las proposiciones que él mismo articula allí en forma literaria o aforística. El sentido (ético) que no se deja decir (lo indecible) en las proposiciones se muestra - encontrando su lugar apropiado -, bajo la forma estética, poética y literaria del aforismo (Gabriel, 2007, p. 139). De acuerdo con esto, para esta tradición - en la que lo ético y lo estético quedan articulados, hasta formar una composición existencial - el lenguaje (educativo) no sólo tiene la función de nombrar o designar sus objetos o realidades, o traducir los pensamientos (pedagógicos), sino que va en otra dirección: pues comprender el lenguaje, entender una frase o una formulación, está más cerca del acto de comprender, por así decir, un tema musical. No habría, por tanto, como dice Hadot al referirse a la obra de Wittgenstein, tanto "[...] el lenguaje, sino juegos del lenguaje", juegos que se sitúan "[...] en la perspectiva de una determinada actividad, de una situación concreta o de una forma de vida" (Hadot, 2007, p. 19).

Conviene recordar aquí que los argumentos filosóficos, según esta tradición, a menudo hicieron uso de la analogía médica, haciendo de ellos una modalidad de argumentos terapéuticos. Como dijo Epicuro:

\begin{abstract}
Vacío es el argumento de aquel filósofo que no permite curar ningún sufrimiento humano. Pues de la misma manera que de nada sirve un arte médico que no erradique la enfermedad de los cuerpos, tampoco hay utilidad ninguna en la filosofía si no erradica el sufrimiento del alma (Nussbaum, 2003, p. 33).
\end{abstract}

Según esto, y siguiendo el mismo planteamiento de Epicuro, la filosofía es un actividad que asegura una vida floreciente (eudaímōn) por medio de argumentos y razonamientos. El recurso a la analogía médica es importante aquí, pues la medicina es un "[...] arte comprometida e inmersa en la realidad, un arte que actúa en pragmática colaboración con aquellos a los que trata" (Nussbaum, 2003, p. 41). La salud, como la formación, no existe en ninguna clase de eternidad sin devenir, y en ningún mundo suprasensible; no está aparte de la gente: de sus vidas, sus sufrimientos y de sus placeres. Es parte integrante de sus formas de vida, completamente singularizadas. De ahí que la investigación, en el sentido de una búsqueda, de una exploración filosófica (sobre la educación), esté siempre limitada por las apariencias - es decir, por la experiencia humana -, y aunque no exista una forma de confirmar sus resultados comparándolos con una realidad extra-experiencial, no por eso es menos cierto que de lo que se trata ahí es de una búsqueda de la verdad.

Esa búsqueda, o más bien, ese encuentro, con la verdad pasa, entonces, por cierto trabajo de transformación del sujeto sobre sí mismo; un cuidado de sí. Las condiciones que definen la verdad del caso no son condiciones, extrínsecas o intrínsecas, en sentido epistemológico, sino condiciones de carácter ético y existencial: se trata de un actitud general, de un modo de considerar las cosas, de estar en el mundo, de 
Filosofía de la Educación

realizar acciones y tener relaciones con los demás; es una actitud con respecto a uno mismo, con respecto a los otros, con respecto al mundo; es una determinada manera de mirar y de prestar atención; es un ejercicio, o una serie de ejercicios, de pensamiento que se vuelcan sobre uno mismo y determinan de terminadas prácticas de transformación sobre uno mismo.

Aunque estas dos tradiciones que he descrito brevemente son, en parte, rivales, hay que advertir que, al mismo tiempo, se complementan. Tal vez por eso no debamos oponer una filosofía entendida como un puro discurso a una concepción de la filosofía como búsqueda de la sabiduría, consistente en una forma de vida. Como señala Hadot: "La filosofía, en la medida en que es un esfuerzo hacia la sabiduría, debe ser por tanto a la vez e indisolublemente discurso crítico y ejercicio de transformación de uno mismo" (Hadot, 2007, p. 28). Si las he presentado con cierto tono de rivalidad, o de oposición, es con el objeto de hacer más claro tanto sus posibilidades como sus límites a la hora de pensar una filosofía de la experiencia educativa.

La primera tradición, entonces, cree que la investigación sobre la educación, filosóficamente hablando, pasa por un momento más o menos privilegiado de conocimiento, dentro del cual el sujeto debe mantener una suerte de distancia crítica, como la he llamado, con la realidad, pues se estima que hay una verdad antes del conocimiento y que un modo determinado de conocer garantiza. Per se trata de un modo de conocer metódico, claro, algo que debe suprimir los encuentros azarosos con la realidad y las implicaciones subjetivas, es decir, el trabajo que sobre sí mismo debe hacer el sujeto para acceder, o tener derecho de acceso, a la verdad. En cambio, la segunda tradición, inscrita en esa historia antigua de la filosofía como forma de vida, es decir, como resultado de una elección existencial aconseja una presencia mayor del sujeto en la realidad que pretende conocer: pues no se trata de examinar la realidad, o pretender hacerlo, con objetividad, neutralidad o imparcialidad, sino de una transformación de sí mismo, realizada a base de una serie de ejercicios (espirituales, en el sentido griego, o de pensamiento), que son los que crean en nosotros las condiciones de la percepción de la verdad. La verdad no está antes, sino después. La metáfora médica es interesante aquí, pues incorpora al hacer filosófico un arte terapéutico de curación, cuidado y conducción de la propia vida, del arte de vivir, de las artes de la existencia. Entonces, el saber de la educación no es ya pedagógico, sino psicagógico. Por fin, la apelación a la distancia poética (el arte de situarnos ni muy lejos ni muy cerca de las justas, sino en la distancia apropiada, justa) no es meramente anecdótica.

Debo insistir en esto que, en mi propio aprendizaje, constituye un aprendizaje tardío. Entiendo lo poético en relación a una modalidad de tiempo fugaz, instantáneo (un ahora). Algo así como lo que fulgurantemente aparece, se muestra, se revela y que logramos captar al vuelo (del tiempo). Sería algo así como una ocurrencia, en el sentido de algo que

718 Educação \& Realidade, Porto Alegre, v. 38, n. 3, p. 703-730, jul./set. 2013 Disponível em: <http://www.ufrgs.br/edu_realidade> 
aparece de improviso, o como un ocurrir o un ocurrírsele a alguien. Por ejemplo, si leo los versos de Sologuren: "Nada dejé en el papel salvo la sombra de mi inclinada cabeza" (Sologuren, 1999, p. 153), llego a considerar que un verso así debió ser, en el poeta, una fulgurante aparición, una súbita revelación en él. Es un verso de una exactitud plena en la imagen que propone. No podría haberse escrito, ni dicho, de ningún otro modo: su forma se corresponde con la tensión de lo que dice o trata de evocar. El poeta ha dejado ser ese verso en él, y lo ha cazado al vuelo, lo tomo a mano (manu tenere) y permitió, sin demora, su presencia. Un momento poético es algo parecido a lo que un verso como este trata de capturar. O mejor: es lo que un verso como este de hecho singulariza, sintetiza, toma, incorpora. Que aparezca así proporciona una intensidad, un placer, o quizá simultáneamente un dolor, derivados del hecho de haber podido contener de ese modo lo que contiene. Tranquiliza y duele. Y en él hay un mundo, en efecto, toda una serie anterior de cosas que ocurrieron, que pasaron. Que le acontecieron a alguien.

En su ensayo Bartleby o de la contingencia, Agamben habla de los experimentos sin verdad ${ }^{5}$. Recuerda allí que este concepto fue acuñado por Walter Lüssi a propósito de Robert Walser, y con él se refiere a “[...] una experiencia caracterizada por el desplazamiento de toda relación con la verdad" (Agamben, 2011, p. 119). En su poesía, Walser parece negarse a conocer el ser de algo en cuanto algo, y Agamben intenta elevar este concepto a paradigma de la experiencia literaria. En efecto, los experimentos, frecuentemente utilizados en la ciencia, también se pueden adoptarse en el terrero poético, en el literario y en el pensamiento; solo que estos últimos no conciernen a la verdad o a la falsedad de una hipótesis, o a la verificación o a la falsación, sino que cuestionan el ser mismo, antes o más allá de su verdad o falsedad. Son experimentos sin verdad, porque en ellos no se trata de la verdad, a la cual no se niega carta de naturaleza, sino que se suspende su poder, por así decir, coactivo. En un experimento con verdad lo que se pone a prueba, o lo que se arriesga, es un saber, una hipótesis. Pero en un experimento sin verdad lo que se pone en juego es el propio ser:

\begin{abstract}
Quien se aventura en ese experimento no arriesga tanto la verdad de sus enunciados como su propio modo de existir, y realiza en el ámbito de su historia subjetiva una mutación antropológica que es, a su manera, no menos decisiva de lo que fue para el primate la liberación de la mano en la posición erecta o para el reptil la transformación de las extremidades delanteras que lo convirtió en pájaro" (Agamben, 2011, p. 120).
\end{abstract}

Allí donde una verdad ha de ponerse a prueba, o donde su presencia impone un límite, la experiencia auténtica no es posible. En pedagogía, debido a su fuerte componente normativo (tanto en sentido moral como técnico) la verdadera experiencia es, en el fondo, de carácter muy limitado. Mi apelación a lo literario y a lo poético, entonces, responde a este deseo de hacer valer la experiencia como algo que, necesariamente, 
pasa por atrevernos a experimentarla sin condicionarla a una verdad que, por conocida ya, nada nuevo nos aporta en volver a descubrirla al final de una trayectoria.

\title{
Ejercicio de Pensamiento y Gestualidad
}

Tal y como ahora soy capaz de percibirlo, la filosofía de la educación consiste, entonces, en una serie de ejercicios de pensamiento, no simplemente experimentos mentales, sino ejercicios de la mente y del cuerpo: espirituales, en el sentido griego del término: interiores al sujeto.

Tales ejercicios de pensamiento evocan, pues, los ejercicios espirituales a los que se ha referido Hadot en su tentativa de recuperación y actualización de la filosofía antigua. Aunque, como el mismo Hadot reconoce, puede que esta expresión no sea muy afortunada, sirve para designar un tipo de actividad, siempre del género discursivo - ya sea racional o imaginativa - "[...] dirigida a modificar, en sí misma o en los demás, la manera de vivir y de ver el mundo” (Hadot, 2007, p. 19). Se trata de unos ejercicios en los que el sujeto tiene la tarea de enfrentarse consigo mismo, haciéndose presente en lo que piensa y en lo que hace. Esta capacidad para hacerse presente en el propio presente, y para vivir su acontecimiento, es tanto como vivir lo que Goethe llamaba la salud del momento (Hadot, 2010).

La filosofía de la educación, entendida como la estoy tratando de pensar aquí, trata de dar respuestas, y sobre todo formularse preguntas, sobre la vida y la experiencia educativas, para lo cual necesita prestar especial atención a las experiencias de la educación. Cuando digo que la filosofía de la educación es un ejercicio de pensamiento, o una serie de ellos, tengo en mente la formulación que de esta noción realizó Hannah Arendt, al definir sus ejercicios de reflexión política en Entre el pasado y el futuro:

\begin{abstract}
Se trata de ejercicios de pensamiento político, tal como surge de la realidad de los incidentes políticos (aunque esos incidentes se mencionan sólo de manera ocasional) [...] Estos ejercicios se mueven entre el pasado y el futuro, razón por la cual contienen tanto críticas como experimentos, pero los experimentos no procuran dibujar una especie de futuro utópico, y la crítica del pasado, de los conceptos tradicionales, no busca un desprestigio [...] Me parece, y espero que el lector esté de acuerdo, que el ensayo como forma literaria posee una afinidad natural con los ejercicios que tengo en mente (Arendt, 1996, p. 20).
\end{abstract}

Este tipo de ejercicios de pensamiento no tienen como propósito prescribir, es decir, orientarnos según reglas fijas en la actividad del pensar: "Su único objetivo es adquirir experiencia en cuanto a cómo pensar; no contienen prescripciones sobre qué hay que pensar ni qué verdades deben sustentar. Más aún, no pretender restablecer el hilo roto de la tradición" (Arendt, 1996, p. 20).

720 Educação \& Realidade, Porto Alegre, v. 38, n. 3, p. 703-730, jul./set. 2013 Disponível em: <http://www.ufrgs.br/edu_realidade> 
Tenemos que aprender a pensar sin la mediación de la tradición, y esto significa que el pensamiento sólo puede contar ya con la experiencia de lo que acontece: "Mi tesis es que el propio pensamiento surge de los incidentes de la experiencia viva y debe seguir unido a ellos a modo de letrero indicador exclusivo que determina el rumbo" (Arendt, 1996, p. 20). El pensar es apertura a la experiencia, que es la que da que pensar. Para Arendt pensar es vivir, y vivir es tener que pensar. Y no hay pensamiento sin riesgo. Pensar, como vivir, es exponerse: "La necesidad de pensar sólo se puede satisfacer pensando, y los pensamientos que tuve ayer satisfarán hoy este deseo sólo porque los puedo pensar de nuevo" (Arendt, 1996, p. 20).

Un filosofar así, como he señalado, no establecería una distancia protectora frente a la realidad - que pensamos a costa de mantenernos alejados de ella -, sino una presencia poética, que siempre es una relación corporal o conocimiento encarnado. Es la distancia que en cada ocasión adoptamos para ver (y estar en) lo que hay. Pues la realidad no es tanto un objeto de conocimiento o una representación como un acontecimiento, es decir, presencia. Y ese hacernos presentes en la realidad requiere la adopción de una distancia apropiada, una presencia poética. Porque ni en el demasiado-cerca ni en el demasiado-lejos vemos ni sabemos nada.

La reflexión filosófica sobre la educación plantea, por tanto, diversas clases de interrogantes, como por ejemplo: ¿En qué consiste una experiencia educativa?, ¿Qué vale la pena conocer y estudiar?, ¿Qué significa dudar? ¿Tiene algún valor educativo el escepticismo?, ¿Qué se entiende por aprendizaje y desarrollo humano?, ¿En qué consiste afirmar la dimensión educativa de la enseñanza o del aprendizaje?, ¿ Se puede anticipar lo que alguien va a aprender?, ¿Qué nos mueve a aprender?, ¿En qué consiste un aprendizaje moral?, ¿Qué significa constituirse en un sujeto moral?, ¿Qué es una educación política?, ¿Se puede educar un buen ciudadano?, ¿Qué significa enseñar?, ¿Cuál es el centro de la relación pedagógica?, ¿Cuál es la relación entre el poder y la autoridad en la escena educativa?, ¿ Se puede enseñar al arte de vivir?, ¿ Se aprende a morir?, y un larguísimo etcétera.

Estas preguntas remiten, no a cuestiones atemporales, ni a esencia invariable alguna, sino a interrogantes existencialmente abiertos sobre lo que significa ser un adulto, estar educado o formándose, y otras, con el objeto de reinventar lo que significa ser humano de un modo, no abstracto, sino estrictamente singular. En la medida que la filosofía (de la educación) tiene como tarea construir conceptos, la abstracción tiene también un lugar asignado, porque la abstracción es imprescindible para conocer. Recordemos que la etimología de este término se refiere a reunir o capturar varios objetos, con el fin de convertir lo múltiple en uno, pues nada desconcierta a la razón humana que el desorden. Ahora bien, el problema no reside ahí, sino en otro lugar: cuando las relaciones (sociales, políticas, éticas o pedagógicas) se pretenden gobernar bajo las

Educação \& Realidade, Porto Alegre, v. 38, n. 3, p. 703-730, jul./set. 2013.

Disponível em: <http://www.ufrgs.br/edu_realidade> 
Filosofía de la Educación

leyes de la abstracción. Como le pasa a la ética, la educación tampoco admite la abstracción de conceptos. Así, cuando las relaciones humanas llegan al punto de transformar las relaciones instrumentales en relaciones morales la abstracción pierde todos sus pretendidos derechos.

Lo importante aquí no son tanto las ideas generales como las cuestiones singulares que se traducen en determinados gestos. Giorgio Agamben ha dicho que "[...] una época que ha perdido sus gestos está obsesionada a la vez por ellos" (Agamben, 2001, p. 50). Recordemos que en De lengua latina, Marco Terencio Varrón inscribía el gesto en la esfera de la acción, señalando que lo distintivo del gesto es que por medio de él ni se produce ni se actúa, sino que su propio hacer consiste en un asumiry un soportar: el gesto abre la esfera del ethos como una esfera propia de lo humano por excelencia. La pregunta es: ¿̇de qué modo es soportada y asumida una acción, de qué forma un simple hecho se convierte en un acontecimiento? No, desde luego, desde la mera representación de una esfera de medios encaminados a una serie de objetivos predeterminados. Es en el propio gesto, en su mostrarse y hacerse visible, en su presentarse y en su aparecer, donde el gesto comunica lo que es. El gesto es “[...] comunicación de una comunicabilidad” (Agamben, 2001, p. 55): pura presencia. Veamos esto en cierta traducción pedagógica.

En su libro Mal de escuela, el escritor francés Daniel Pennac refiere su experiencia de más de 25 años como profesor de lengua francesa, y recuerda su propia historia de mal alumno, de zoquete, como él mismo dice. Todo el relato gira en torno a los gestos que nos permiten volver a hacernos presentes en lo que hacemos. ¿Cómo lograrlo? Con gestos que, en su carácter fragmentario y singular, dicen de qué se trata:

Pasar lista por la mañana. Oír tu nombre por la voz del profesor es como un segundo despertar. El sonido que tu nombre hace a las ocho de la mañana tiene vibraciones de diapasón. No puedo prescindir de pasar lista [...] Llamo a mis bribones mirándoles, les recibo, les nombro, uno a uno, y escucho su respuesta. [...] Un mínimo segundo en el que el alumno debe sentir que existe para mí, él y no otro (Pennac, 2008, p. 117).

El gesto encierra una única certeza: la presencia de los alumnos, en lo que hacen y ante sí mismos, depende enteramente de la presencia del profesor, en lo que él mismo hace, en lo que enseña y ante sus propios alumnos, como dice de nuevo Pennac: "De mi presencia en la clase entera y en cada individuo en particular, de mi presencia también en la materia, de mi presencia física, intelectual y mental, durante los cincuenta y cinco minutos que durará mi clase" (Pennac, 2008, p. 111).

El discurso pedagógico piensa algunos de estos gestos, pero traducidos ya a categorías muy generales (familia, profesor, alumno, relaciones didácticas, competencias, y otras). Lo interesante de la aportación de esa segunda tradición de la que he hablado está en otro sitio: se trata de volver a pensar eso que nos pasa (como aprendices, como pa- 
dres, como hijos, como educadores, como profesores o maestros), en un presente que es como una brecha entre dos tiempos (pasado y futuro, antes y después), y es ahídonde el sujeto se pregunta por aquello que ve, aquello que piensa, aquello que le acontece. En esa brecha del tiempo, el sujeto de la experiencia piensa, y su pensamiento es una especie de ensayo o ejercicio; un ejercicio de comprensión cuyo resultado final no alcanza a ver ni puede anticipar. Podríamos formularlo con la siguiente pregunta: ¿Qué significa de verdad ser padre, o ser hijo, ser un maestro o profesor, ser un aprendiz o ser un discapacitado, más allá de todo discurso impuesto que dicta ya cómo deben ser pensadas cada una de esos modos de ser y de encontrarse en el mundo? $i$ Se pueden volver a pensar otra vez, de otro modo, más allá de ser palabras importantes para una pedagogía, esas voces: padre, hijo, profesor, alumno, aprendiz...? Estas preguntas no son superfluas; más bien apuntan a algo que es esencial, pero no vemos porque nuestros ojos se han acostumbrado a mirar sin darse cuento de lo que ven, sin prestar atención. Ni profesores ni alumnos sabemos, quizá, utilizarnos a nosotros mismos en lo que hacemos: no ponemos todo nuestro ser en lo que hacemos. A lo que apuntan estas consideraciones es al hecho de que en pedagogía pasa, como sucede con casi todo lo demás, que cuando dejamos de reflexionar sobre los casos particulares, sobre lo singular, buscamos el refugio en la buena doctrina, la autoridad competente o el precepto legislativo; en lo que sea; y, como dice Pennac, "[...] luego nos plantamos sobre certezas que nada hace vacilar, ni tan siquiera el desmentido cotidiano de la realidad" (Pennac, 2008, p. 120).

\title{
Telón. Amor y Filosofía: un final proustiano
}

Hablar de filosofía es hablar del saber de una cierta clase de amor (y del amor hacia un cierto tipo de saber). La filosofía tiene que ver con el amor y con la amistad, ambas constituidas como bases del pensar. La filosofía de la educación se ocupa de lo que esto significa: la experiencia de un vínculo, de una relación, que une amando a dos. Y es esto lo que convierte a un simple profesor en un maestro. Pues éste

\begin{abstract}
[...] a diferencia del profesor, no se preocupa por enseñar aptitudes o capacidades a aquel a quien guía [...] El maestro es quien se preocupa por el cuidado que el sujeto tiene respecto de sí mismo y quien encuentra, en el amor que siente por su discípulo, la posibilidad de preocuparse por la preocupación de éste en relación consigo mismo (Foucault, 2002, p. 73).
\end{abstract}

En filosofía, el amigo ya no designa solamente a un personaje extrínseco, una circunstancia empírica, sino una presencia intrínseca al propio pensamiento; una categoría viva. Los griegos, que sabían de eso, sometieron a la figura del amigo a una torsión radical, al vincularlo a la búsqueda de la sabiduría. Aunque desde entonces el discurso filosófico se haya extraviado muchas veces, hasta perder esa orientación origina- 
ria, algo nos queda; es la sensación de que el amigo es, filosóficamente hablando, una condición para el ejercicio del pensamiento. Porque los conceptos, cuya construcción es tarea primordial de la filosofía, necesitan personajes conceptuales que contribuyan a definirlos. Esa búsqueda de la sabiduría, conectada con la búsqueda de la verdad, es una revelación, una aparición súbita que depende del azar. Encontramos la verdad, como pensaba Proust, por encuentros casuales y fortuitos, y nunca, o casi nunca, cuando nuestra inteligencia se aplica voluntariamente a su conquista.

El amor, como experiencia, lo que podríamos llamar amor-pasión, tiene un carácter bastante cercano como Proust lo entendía en À la recherche: algo atroz, ambivalente o diabólico. Como dice Estela Ocampo en su bellísimo ensayo sobre Proust:

\begin{abstract}
$\mathrm{El}$ amor es esencialmente contradictorio [...] El amor es una especie de trampa mortal, de la cual no es posible escapar, un sentimiento cuyo destino final el amante conoce de antemano. Solamente quien puede hacerle sufrir puede también, en virtud del poder que le ha otorgado sobre sí mismo, traerle la calma (Ocampo, 2006, p. 20-21).
\end{abstract}

Este carácter contradictorio y diabólico del amor se encuentra en algunas representaciones iconográficas de Cupido (Curi, 2009). A partir del siglo XIII hay un cambio sustancial de las artes figurativas en las formas en las que es representado el amor. Con anterioridad, Cupido es representado como un niño desnudo y alado, con arco y flechas y, en ocasiones, con una antorcha. En algunos casos los arcos son dos: uno está destinado a encender el amor, el otro para extinguirlo. Los rasgos con los que es representado Cupido poseen un elevado componente simbólico: el aspecto infantil se corresponde con el comportamiento pueril de los amantes, su desnudez con una actitud de exhibición declarada, las alas simbolizan el comportamiento volátil e inestable de los estados de ánimo amorosos, y los dardos o las flechas evocan las heridas infligidas por las punzadas eróticas.

Poco a poco esta representación se va modificando, y se introducen nuevos rasgos, y en concreto uno que es esencial: la ceguera de Cupido. Es un niño ciego. Contrariamente a lo que dice Platón, para quien el amor penetra en el ánimo de los amantes a través del sentido de la vista, a Cupido se le va a representar como un niño ciego, ceguera que simbolizará la forma con la que el niño hiere con sus flechas a los amantes. Lo hace a ciegas, sin distinción de sexos, edades o clases sociales. Además, los que son heridos por sus flechas quedan ciegos, es decir, se quedan sin luz, sin capacidad de razonar, sin capacidad de juicio. Cupido ciego no sabe quienes son sus víctimas, y éstas, una vez que han sido heridos, no saben atenerse a un comportamiento racional.

La cuestión de la ceguera, desde el punto de vista filosófico, es muy importante, pues el philo-sophós, el amante del saber es, al mismo tiempo, alguien en cierto modo ciego (por no poseer la luz del saber al 
que aspira) y lúcido, una vez alcanzado. El motivo de la ceguera está también en el Prometeo, de Esquilo, que ha infundido a los hombres ciegas esperanzas (typhlás elpídes). La esperanza desempeña una función salvadora para los hombres allí donde la tejnai, las artes y las técnicas especializadas, se habían revelado ya insuficientes. Este poder salvador se deriva de la capacidad de la esperanza de disuadir a los hombres de depositar su mirada fija en el fin de la vida, es decir, de cegarlos con respecto al final que se cierne sobre todos. Así, Elpís, la esperanza, es ciega al ser repartida a todos por igual, y porque su misión es impedir que los hombres miren de frente a la muerte, que es su inevitable final. La ceguera, entonces, es un don, porque garantiza la supervivencia de los hombres, evitándoles caer en la desesperación. Aquí, la esperanza tiene que ver con cierta esperanza de sentido; esperanza en que la última palabra no sea la nada. La esperanza en las pequeñas cosas es como la energía de la vida: esperanza de hechos extraordinarios y de hechos banales, normales, cotidianos, entendida como una forma de amor a lo cotidiano, al día a día. Esperar constantemente el día a día es una forma de amar todos los días, el tiempo que pasa y nos pasa, la cotidianidad del tiempo vivido.

Pero volvamos a Cupido. Su ceguera indica algo así como una deficiencia radical, denota algo negativo, pues Cupido se unió a la Noche, a la Infidelidad, a la Muerte, a la Fortuna. De ahí deriva la idea de que el amor embota los sentidos y las capacidades intelectuales de los amantes. Entre amor y conocimiento se inicia una relación de mutua incompatibilidad. Enamorarse es, entonces, volverse loco, perder la razón, ser incapaz de discernir y de argumentar con claridad. O amor o conocimiento, esta parece ser la disyuntiva.

La apuesta por un conocimiento desgajado del amor se sostiene en la suposición de que el conocimiento más evolucionado y maduro es el conocimiento a-pático, aquél que sabe resguardarse de todo tipo de condicionamientos pasionales o afectivos. Es el conocimiento distanciado (crítico, por tanto) de la realidad y del mundo. Y, sin embargo, sabemos que no se aprende a conocer más que aquello que se ama profundamente; todo gran amor es hijo de un gran conocimiento, de un conocimiento apasionado.

Según Marcel Proust el amor es importante para el filósofo, ya que le ofrece múltiples enseñanzas, pero atroz para el amante. El amor enseña unas cosas al filósofo, al pensador, y otras muy distintas a quien experimenta sus dardos mortíferos. Sin embargo, el filósofo es un amante; pero es un amante diferente de los múltiples amantes que la historia de la literatura nos ofrece. Que el amor sea, como dice Proust, atroz, no impide que se busque como uno de los bienes más preciados. Sin embargo, el amor es esencialmente contradictorio. En toda experiencia amorosa el sufrimiento, la crueldad, la maldad están siempre inevitablemente presentes, del mismo modo que la exaltación, el placer, la vitalidad y la felicidad.

Educação \& Realidade, Porto Alegre, v. 38, n. 3, p. 703-730, jul./set. 2013.

Disponível em: <http://www.ufrgs.br/edu_realidade> 
$\mathrm{Y}$, al mismo tiempo, es una fuente de verdad, de certeza, que nos enseña a caer a través del más afinado y cruel de sus instrumentos: el sufrimiento. Aquí reside la genuina fuente del conocimiento del amor. Es por el dolor que produce el desengaño amoroso la razón por la cual el amante evidencia que la tentativa de captar el amor solo intelectualmente es la mejor manera de evitar amar. No se trata solo de una evidencia resultado de nuestra propia experiencia individual y solitaria como amantes, la que cada uno de nosotros sin duda dispone. Lo que Proust parece querer decir, al mismo tiempo, es otra cosa: nuestra inteligencia, nuestra buena voluntad para pensar y para descubrir la verdad, siempre termina por fracasar, como la memoria, que tiene más de involuntaria que de voluntaria: "El dolor obliga a la inteligencia a buscar, al igual que algunos placeres insólitos ponen en marcha la memoria” (Deleuze, 1996, p. 33).

En uno de los volúmenes de À la recherche, el que está destinado a la huida de Albertine, Françoise dice: "Madmoiselle Albertine se ha marchado". Tan solo un momento antes, el narrador creía estar seguro que ya no la amaba. Pero, ahora, la noticia de su partida le provoca una reacción intensa e indominable, una angustia abrumadora: "¡Cuánto más lejos psicológicamente llega el sufrimiento que la psicología!” (Proust, 2010, p. 8), señala el narrador.

Sí, hacía un momento, antes de la llegada de Françoise, yo había creído que ya no amaba a Albertine, había creído no haber dejado nada de lado; como meticuloso analista, había creído conocer bien el fondo de mi corazón. Mas nuestra inteligencia, por lúcida que sea, no puede percibir los elementos que lo componen y que permanecen insospechados mientras del estado volátil en que subsiste la mayor parte del tiempo un fenómeno capaz de aislarlos no les haya hecho sufrir un principio de solidificación. Me había equivocado creyendo ver claro en mi corazón. Mas ese conocimiento que no me habrían dado las más finas percepciones de la mente, acababa de aportármelo, duro, resplandeciente, extraño, como una sal cristalizada, la brusca reacción del dolor. Estaba habituado a tener a Albertine a mi lado, y de repente el Hábito me mostraba un nuevo rostro. Hasta ese momento lo había considerado sobre todo como un poder aniquilador que suprime la originalidad e incluso la conciencia de las percepciones; ahora lo veía como una divinidad temible, tan clavada en nosotros, con su insignificante rostro tan incrustado en nuestro corazón que si se despega, si se aparta de nosotros, esa deidad que apenas distinguíamos nos inflige sufrimientos más terribles que ninguna otra y es entonces tan cruel como la muerte (Proust, 2010, p. 8).

El impacto producido por la pérdida de Albertine y el correspondiente surgimiento del dolor muestran al narrador que sus anteriores teorizaciones eran una forma de autoengaño racionalizado, al acos- 
tumbrar, y habituar, al narrador a una falta concepción de sí mismo y de lo que sentía con respecto a su amante. Proust habla de signos trazados como con tinta invisible, pistas que, en su propia manifestación, daban cuenta de lo que tenía que haber sabido y no supo, a saber: que Albertine podría, como de hecho ocurrió, marcharse en algún momento.

Las palabras de Françoise le han quitado una máscara - la de su falsa creencia anterior sobre su desamor por Albertine - y le proporciona una nueva certeza que le angustia: ahora, Marcel sabe con seguridad que la sigue amando. Esas palabras son como un catalizador que crea algo que antes no estaba allí: su sufrimiento. Las palabras tienen ese poder: crear lo que no estaba.

El sofista Gorgias definía la operación del logos como el más pequeño y el más imperceptible de los cuerpos. Decía que el lenguaje es un gran soberano que con el más pequeño y el más imperceptible de los cuerpos (la palabra), realiza los actos más divinos. En Marcel, aquellas palabras de Françoise producen en él un cambio, una metamorfosis: Marcel deviene un hombre que sufre al descubrir, por azar, por casualidad, una verdad: que amaba a Albertine. Llega a un conocimiento de su amor por ella. Mientras Proust razonaba, antes de la partida de Albertine, que de hecho no la amaba, parecía estar seguro de la fe, de la creencia, que sus razonamientos le proporcionaban. Pero esas palabras, lanzadas al azar por Françoise, le proporcionan otra evidencia; que

\begin{abstract}
La inteligencia no es el instrumento más sutil, más potente, más apropiado para aprehender la verdad [...] es simplemente una razón más para comenzar por la inteligencia y no por un intuitivismo del inconsciente, por una fe inconmovible en los presentimientos. La vida es la que - poco a poco, caso por caso - nos permite advertir que lo más importante para nuestro corazón o para nuestro juicio no lo descubrimos mediante el razonamiento, sino mediante otras facultades (Proust, 2010, VI, p. 11).
\end{abstract}

Este es el punto en el que este aprendiz, y con esto termino, se encuentra. Es un sensibilidad extraña la que, en los últimos años, se ha movilizado, una percepción distinta de las cosas, una conciencia más aguda de la impotencia - que es la cara desventurada de la potencia aristotélica, la misma que hoy tanto cuesta nombrar, en ese permanente, y supuestamente democrático, elogio del Yes, we can.

Proust proporciona una inmensa lección a la filosofía, y a la filosofía de la educación, cada vez que subraya el componente involuntario de la memoria y de la inteligencia, cada vez que subraya que sus personajes se encuentran con la verdad a base de encuentros azarosos con signos que se empeñan por traducir, interpretar y perseguir. La obra de Proust está repleta de fragilidades cotidianas y descubrimientos asombrosos. Así, el narrador-niño (el pequeño Marcel de À la recherche), creía que desde su casa en Combray se iba por el mundo a través de dos caminos divergentes, que jamás se encontrarían: uno era el camino de Guer- 
mantes (que simboliza la esfera de la aristocracia y la nobleza), y el otro el camino de Méséglise (que simboliza el mundo de la burguesía financiera). Tres mil páginas después, ese niño es casi un anciano residente de París que habrá aprendido que el camino de Méséglise conduce al de Guermantes. Esto es, por supuesto, meramente simbólico. Lo que interesa, y es esencial aquí, es que el aprendizaje del narrador se resolverá sabiendo que el mundo tiene varios costados, como toda formación - y como todo aprender -, y que por cualquiera de ellos se llega hasta el mundo. Deleuze sugiere esta idea en su ensayo Proust y los signos. El lado Méséglise y el lado de Guermantes son los dos lados (simbólicos) de una misma formación:

\begin{abstract}
Proust insiste constantemente en esto: en tal o cual momento el protagonista no sabía determinada cosa, lo aprenderá más tarde. Estaba bajo determinada ilusión de la que acabará por desprenderse. De ahí el movimiento de decepciones y revelaciones que marca el ritmo de toda la Recherche (Deleuze, 1996, p. 12).
\end{abstract}

Aprender, cuando tiene que ver con descubrir verdades que nos hacen adultos, está vinculado a la posibilidad de poder comparar los diversos lados del mundo, las diversas ficciones o narraciones simbólicas con las que narramos el mundo y su entrada en él.

Recebido em 2 de abril de 2013 Aprovado em 14 de junho de 2013

\title{
Notas
}

1 Cf. Chalier (2008) y Stiegler (2008)

2 Sobre el ensayo: Adorno (2003) y Olbadia (1995).

3 Ambas tradiciones, en realidad, coinciden con lo que Foucault llamó el "momento cartesiano" y el "momento socrático" de la filosofía. Cf. Foucault (2002, p. 15-38).

4 Sigo aquí a: Masschelein (2011) y Masschelein (2009).

5 Debo agradecer a Florelle D'Hoest que haya yo caído en la cuenta de la importancia de esta noción de Agamben, una con la que ella misma trabajó durante cuatro meses, por brillante iniciativa suya, con nuestros alumnos del tercer curso de Filosofía de la Educación en el Grado de Pedagogía de la Facultad de Educación (Universidad Complutense de Madrid), durante el curso 2012-13).

\section{Referencias}

ADORNO, Theodor. El Ensayo como Forma. In: Notas sobre Literatura, Obra Completa, 11. Madrid: Akal, 2003. P. 11-34

AGAMBEN, Giorgio. El Hombre sin Contenido. Madrid: Árlea, 1988.

AGAMBEN, Giorgio. Medios Sin Fin. Valencia: Pre-Textos, 2001.

AGAMBEN, Giorgio. Bartleby o de la Contingencia. In: PARDO, José Luis. Preferiría no Hacerlo. Valencia: Pre-Textos, 2011. 
ARENDT, Hannah. Entre el Pasado y el Futuro. Barcelona: Península, 1966. AUBENQUE, Pierre. El Problema del Ser en Aristóteles. Madrid: Taurus, 1974. BÁRCENA, Fernando. El Aprendiz Eterno. Filosofía, educación y el arte de vivir. Buenos Aires: Miño \& Dávila, 2012.

BÁRCENA, Fernando. El Alma del Lector. La educación como gesto literario. Bogotá, Colombia: Asolectura - Primero el Lector, 2012.

CHALIER, Catherine. Transmettre, de Génération en Génération. París: Buchet/Chastel, 2008.

CURI, Umberto. Mitos de Amor. Filosofía del eros. Madrid: Siruela, 2009.

DELEUZE, Gilles. Diálogos. Valencia: Pre-textos, 2004.

DELEUZE, Gilles; GUATTARI, Félix. Qu'est-ce que la Philosophie? París: Les Éditions de Minuit, 2005

DELEUZE, Gilles. Proust y los Signos. Barcelona: Anagrama, 1996.

DESCOMBES, Vincent. Proust. Philosophie du roman. Paris: Minuit, 1987.

EPICURO. Cartas y Sentencias. Palma de Mallorca: El Barquero, 2007.

FOUCAULT, Michel. La Hermenéutica del Sujeto. Curso en el Collège de France, 1981-1982. México: F.C.E., 2002.

FOUCAULT, Michel. Le Courage de la Verité. Le gouvernement de soi et des autres, II. Cours au College de France, 1984. París: Gallimard-Seuil, 2009.

FOUCAULT, Michel. La Escena de la Filosofía. In: Obras Esenciales. Barcelona: Paidós, 2010.

GABRIEL, Gottfried. ¿La lógica como Literatura? Observaciones sobre el Significado de la Forma Literaria en Wittgenstein. In: HADOT, Pierre. Wittgenstein y los Límites del Lenguaje. Valencia: Pre-Textos, 2007.

GUMBRECHT, Hans Ulrich. Éloge de la Présence. Ce qui échappe à la signification. París: Libella - Maren Sell, 2010.

HADOT, Pierre. La Philosophie comme Manière de Vivre. París: Albin Michel, 2001.

HADOT, Pierre. Wittgenstein y los Límites del Lenguaje. Valencia: Pre-Textos, 2007.

HADOT, Pierre. Elogio de Sócrates. Barcelona: Paidós, 2008.

HADOT, Pierre. No te Olvides de Vivir. Madrid: Siruela, 2010.

HEIDEGGER, Martin. ¿Qué Significa Pensar? Madrid: Trotta, 2005.

HOLMA, Katariina. The Strict Analysis and the Open Discussion, Journal of Philosophy of Education, New Jersey, v. 43, n. 3, 2009.

LARROSA, Jorge. Herido de Realidad y en Busca de Realidad. Notas sobre los lenguajes de la experiencia. In: CONTRERAS, José; PÉREZ DE LARA, Nuria (Org.). Investigar la Experiencia Educativa. Madrid: Morata, 2010.

MASSCHELEIN, Jan. On Fieldwork in Philosophy and the Actual Need for Laboratories. A proposal and invitation. In: Conferencia leída en la International Conference: "Philosophy of Education and the Transformation of Educational Systems", Universidad de Basel, octubre 2009. Documento enviado por el autor. MASSCHELEIN, Jan. Philosophy of Education. Bajo Palabra, Madrid, n. 6, p. 3940, 2011.

NUSSBAUM, Martha Craven. La Terapia del Deseo. Teoría y práctica de la ética helenística. Barcelona: Paidós, 2003.

Educação \& Realidade, Porto Alegre, v. 38, n. 3, p. 703-730, jul./set. 2013 
OCAMPO, Estela. Cinco Lecciones de Amor Proustiano. Madrid: Siruela, 2006. OLBADIA, Claude. L'Esprit de l'Essai. De Montaigne à Borges. París: Éditions du Seuil, 1995.

PARDO, José Luis. La Regla del Juego. Sobre las dificultades de aprender filosofía. Barcelona, Galaxia Gutenberg-Círculo de Lectores, 2004.

PENNAC, Daniel. Mal de Escuela. Barcelona: Mondadori, 2008.

PENNAC, Daniel. Diario de un Cuerpo. Barcelona: Mondadori, 2012.

PLATÓN. Teeteto. Diálogos, vol. V. Madrid: Gredos, 1988.

PROUST, Marcel. En Busca del Tiempo Perdido, vol. VI. Barcelona: Mondadori, 2010.

RUITENBERG, Claudia (Org.). What do Philosophers of Education do? (And how do they do it?). Journal of Philosophy of Education, New Jersey, v. 43, n. 3, 2009 (Special Issue).

STIEGLER, Bernard. Prendre soin de la Jeunesse et des Générations. París: Flammarion, 2008 .

SLOTERDIJK, Peter. Muerte Aparente en el Pensar. Sobre la filosofía y la ciencia como ejercicio. Madrid: Siruela, 2013.

SOLOGUREN, Javier. Vida Continua. Nueva Antología. Valencia: Pre-Textos, 1999.

TAYLOR, Charles. Las Fuentes del Yo. La construcción de la identidad moderna. Barcelona: Paidós, 2006.

VOKEY, Daniel. 'Anything You Can Do I Can Do Better': Dialectical Argument in Philosophy of Education. Journal of Philosophy of Education, New Jersey, v. 43. n. 3, 2009.

WITTGENSTEIN, Ludwig. Observaciones. México: Siglo XXI editores, 1989.

ZORN, Fritz. Bajo el Signo de Marte. Barcelona: Anagrama, 2009.

Fernando Bárcena é catedrático de Filosofia da Educação na Universidad Complutense de Madrid (Espanha). É membro do grupo de pesquisa Políticas educativas e cultura cívica, da Universidad Complutense de Madrid, e do Núcleo de Estudos sobre Filosofia, Poética e Educação, da Universidade Federal Fluminense - UFF. Sua área de pesquisa é a reflexão da filosofia do acontecimento educativo, cobrindo diversas dimensões políticas, éticas e poéticas.

E-mail: fernando@edu.ucm.es 